\title{
Origem e distribuição do plexo lombossacral da paca (Cuniculus paca, Linnaeus 1766)
}

\author{
Maria Gabriela de Oliveira Tonini \\ Tais Harumi de Castro Sasahara * \\ Leonardo Martins Leal \\ Márcia Rita Fernandes Machado \\ Universidade Estadual Paulista, FCAV, UNESP \\ Departamento de Morfologia e Fisiologia Animal \\ Via de acesso Prof. Paulo Donato Castellane s/n, CEP14884-900, Jaboticabal - SP, Brasil \\ * Autor para correspondência \\ tsasahara@gmail.com
}

Submetido em 21/09/2013

Aceito para publicação em 05/03/2014

\section{Resumo}

Considerando a importância da paca como fonte proteica alternativa à população e, em especial, por apresentar características adequadas à pesquisa como modelo experimental, objetiva-se descrever a origem e a distribuição do plexo lombossacral da paca, visando colaborar com o melhor conhecimento de sua morfologia, cuja descrição é escassa na literatura. Foram utilizadas oito pacas adultas (Cuniculus paca) de ambos os sexos, provenientes do criatório do Setor de Animais Silvestres da Faculdade de Ciências Agrárias e Veterinárias da Universidade Estadual Paulista (Unesp) em Jaboticabal; após o óbito, os animais foram fixadas em paraformaldeído $10 \%$ e dissecadas para identificação do plexo lombossacral. Este, em 7 pacas analisadas (87,5\%), originou-se dos ramos ventrais dos nervos espinhais lombares L4, L5, L6 e L7 e dos nervos espinhais sacrais S1, S2 e S3; e em 1 espécime (12,5\%) o plexo lombossacral originou-se de L5, L6, L7, S1, S2 e S3, sem a participação de ramo proveniente de L4. Conclui-se que os nervos que contribuem para formação desse plexo são: nervo genitofemoral, nervo cutâneo femoral lateral, nervo femoral, nervo glúteo cranial, nervo obturatório, nervo isquiático, nervo glúteo caudal, nervo pudendo e nervo cutâneo femoral caudal.

Palavras-chave: Anatomia; Animais silvestres; Inervação; Membro pélvico; Roedor

\section{Abstract}

Origin and distribution of the lumbossacral plexus in lowland paca (Cuniculus paca, Linnaeus 1766). Considering the importance of lowland paca as an alternative protein source to the population and, especially, for showing suitable characteristics for research as an experimental model, we aim to describe the origin and distribution of the lumbossacral plexus in lowland paca, in order to contribute to an improved knowledge on its morphology, whose description is poor in literature. Eight adult lowland pacas (Cuniculus paca) of both sexes were used, obtained from the breeding ground at the Wild Animals Sector of the School of Agricultural and Veterinary Sciences of the São Paulo State University (UNESP) in the town of Jaboticabal; after death, the animals were fixed in 10\% paraformaldehyde and dissected for identifying the lumbossacral plexus. This, in 7 
lowland pacas (87.5\%) analyzed, stemmed from the ventral branches of the lumbar spinal nerves L4, L5, L6, and L7 and from the sacral spinal nerves S1, S2, and S3; and in 1 specimen (12.5\%) the lumbossacral plexus stemmed from L5, L6, L7, S1, S2, and S3, with no participation of a branch stemming from L4. We conclude that the nerves contributing to form this plexus are: genitofemoral nerve, lateral femoral cutaneous nerve, femoral nerve, cranial gluteal nerve, obturator nerve, sciatic nerve, caudal gluteal nerve, pudendal nerve, and caudal femoral cutaneous nerve.

Key words: Anatomy; Innervation; Pelvic limb; Rodent; Wild animals

\section{Introdução}

A paca é um roedor da região neotropical (MONDOLFI, 1972; MATAMOROS, 1982). Esse roedor apresenta alto potencial zootécnico, pois sua carne é muito apreciada para consumo. Esses animais são característicos por apresentar porte médio, facilitando seu manejo: os machos adultos medem, de 60 a 80 $\mathrm{cm}$, do focinho à ponta da cauda; as fêmeas, um pouco menores, medem, de 55 a $70 \mathrm{~cm}$ (MONDOLFI, 1972; BENTTI, 1981); o peso corpóreo varia de 5 a $10 \mathrm{~kg}$, podendo chegar até aos $14 \mathrm{~kg}$ (MATAMOROS, 1982).

Pacas e cutias são citadas como um dos principais itens de alimento na dieta das populações rurais da região dos trópicos (KLEIMAN et al., 1979) e o Brasil está entre os países com criatórios autorizados para fins comerciais (FIEDLER, 1990; MOCKRIN et al., 2005).

Sua importância, além da comercial, toma também o âmbito da ciência, pois as pacas, que são roedores, podem tornar-se boa alternativa para fins de pesquisa, colaborando com o desenvolvimento de investigações vitais ao homem e aos próprios animais (FIEDLER, 1990; MOCKRIN et al., 2005).

O plexo lombossacral é a origem da inervação de toda a região medial da coxa, região lombar e sacral, sendo assim, o seu estudo tem fundamental importância devido às enfermidades dos ramos neurais que podem ocorrer nesta região, que podem causar dificuldades locomotoras, levando à paresia do membro. Outro fator importante é a realização de anestesia peridural, que consiste no bloqueio das fibras nervosas dos ramos espinhais, através da deposição de fármacos anestésicos no canal espinhal, técnica muito utilizada em procedimentos obstétricos, intervenções sobre o reto e até mesmo algumas cirurgias ortopédicas (MASSONE, 1999).
Considerando a importância deste animal como fonte proteica alternativa à população e, principalmente, por apresentar características adequadas para modelo experimental, objetivou-se descrever a origem e a distribuição do plexo lombossacral da paca, visando colaborar com o melhor conhecimento de sua morfologia, cuja descrição é escassa na literatura consultada.

\section{Material e Métodos}

Foram utilizadas oito pacas adultas (Cuniculus paca), quatro machos e quatro fêmeas, provenientes do Setor de Animais Silvestres do Departamento de Zootecnia da Faculdade de Ciências Agrárias e Veterinárias da Universidade Estadual Paulista, Câmpus de Jaboticabal (FCAV-UNESP), que é registrado no Instituto Brasileiro do Meio Ambiente e dos Recursos Naturais Renováveis - IBAMA, como criatório de espécimes da fauna brasileira para fins científicos (cadastro de registro - 482508). Esta pesquisa foi aprovada pelo Comite de Ética no Uso de Aninais (CEUA) da FCAV-UNESP sob número 017754/13. Estes animais foram encaminhados ao Laboratório de Anatomia do Departamento de Morfologia e Fisiologia Animal após virem a óbito por motivos diversos não implicados em patologias que pudessem comprometer as estruturas em estudo.

Os animais foram fixados mediante dissecação, canulação e injeção de solução aquosa de paraformaldeído a $10 \%$ na artéria carótida comum e mergulhados em cubas com esta mesma solução, por no mínimo $72 \mathrm{~h}$. Em sequência, após a fixação das peças, procedeuse a incisão das cavidades abdominal e pélvica para a exposição da face ventral da coluna vertebral e visualização da localização da origem e distribuição dos nervos a serem estudados. 
Para melhor visualização das estruturas nervosas, a região dissecada foi imersa em $60 \%$ de solução alcoólica de ácido acético.

A nomenclatura utilizada neste trabalho baseou-se na Nomenclatura Anatômica Veterinária (INTERNATIONAL COMMITTEE ON VETERINARY GROSS ANATOMICAL NOMENCLATURE, 2012)

\section{Resultados}

Observamos que o plexo lombossacral, em sete pacas analisadas $(87,5 \%)$, originou-se dos ramos ventrais dos nervos espinhais lombares L4, L5, L6, L7 e dos nervos espinhais sacrais $\mathrm{S} 1, \mathrm{~S} 2$ e S3 e em um exemplar $(12,5 \%)$, o plexo lombossacral originou-se de L5, L6, L7, S1, S2 e S3, sem a participação de ramo proveniente de L4. Os nervos contribuidores da formação deste plexo são: nervo genito-femoral, nervo cutâneo femoral lateral, nervo femoral, nervo glúteo cranial, nervo obturatório, nervo isquiático, nervo glúteo caudal, nervo pudendo e nervo cutâneo femoral caudal (Figura 1; Figura 2).

O nervo genito-femoral originou-se em $50 \%$ dos casos dos ramos ventrais do nervo espinhal lombar de $\mathrm{L} 4$, em $37,5 \%$ dos ramos ventrais de L 4 e L 5 e em $12,5 \%$ dos ramos ventrais de L5. O nervo cutâneo femoral lateral originou-se em $87,5 \%$ das peças estudadas, dos ramos provenientes de L 5 e em $12,5 \%$ dos animais, de ramos ventrais dos nervos espinhais lombares L5 e L6. O nervo femoral originou-se em $50 \%$ dos casos estudados dos ramos provenientes de L5 e L6, em 37,5\% dos animais de L5, L6 e L7 e em 12,5\% das peças analisadas de L6 e L7. O nervo glúteo cranial originou-se dos ramos ventrais oriundos de L6 e L7 em 50\% dos casos,

FIGURA 1: Fotomacrografia e esquema da região lombossacral da paca. A- nervo genito-femoral; B- nervo cutâneo femoral lateral; Cnervo femoral; D- nervo obturatório; E- nervo glúteo cranial; F- nervo glúteo caudal; G- nervo isquiático, H- nervo pudendo, I- nervo cutâneo femoral caudal. Escala de barra: $20 \mathrm{~mm}$.

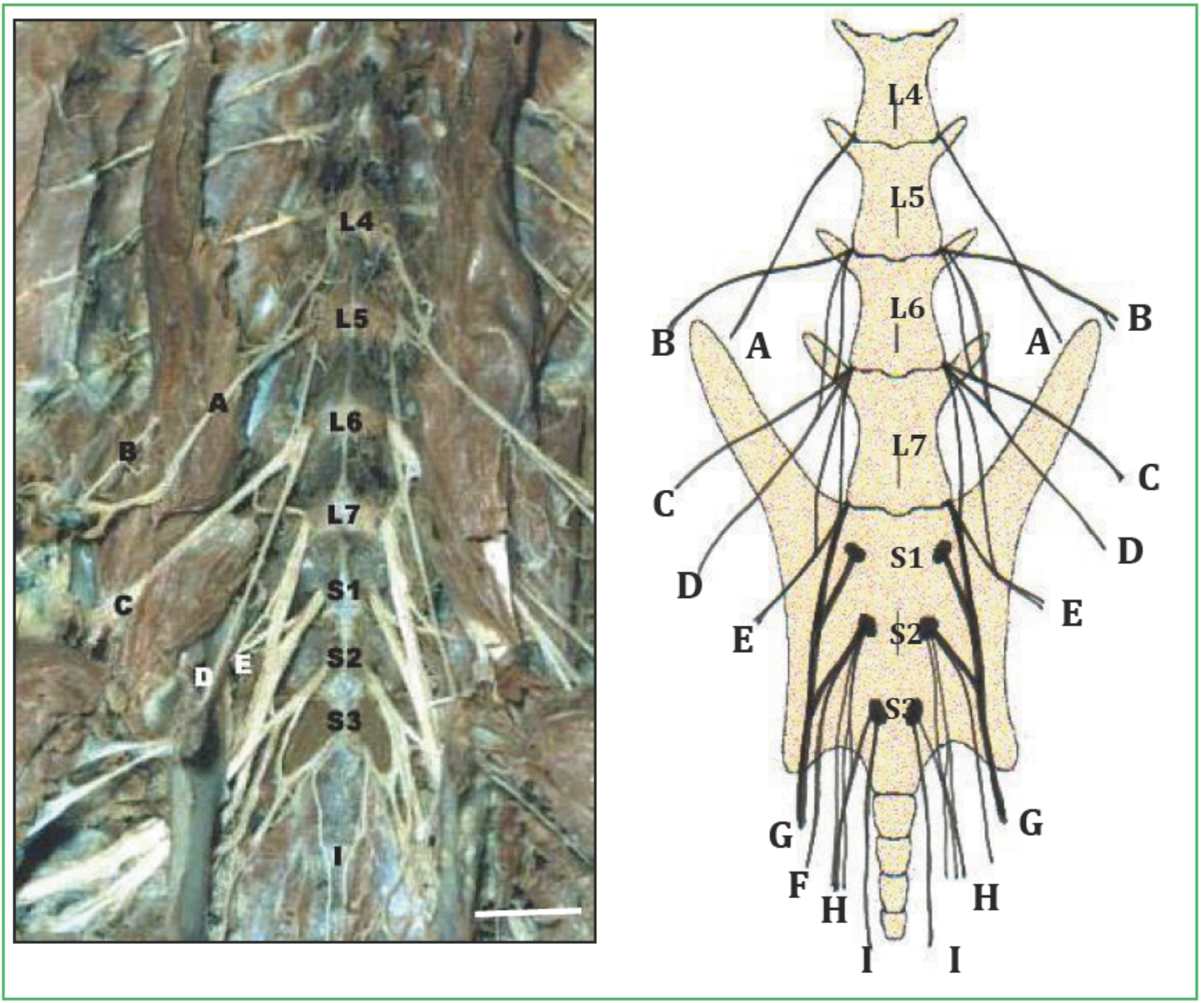


dos ramos ventrais vindos de $\mathrm{L} 7 \mathrm{em} 37,5 \%$ e dos ramos ventrais de $\mathrm{L} 7$ e $\mathrm{S} 1$ em 12,5\% das peças analisadas. Este nervo deixa a cavidade pélvica através do forame isquiático maior, dividindo-se de modo variável, para suprir a musculatura glútea, e o músculo tensor da fáscia lata. O nervo obturatório apresentou-se originado dos ramos ventrais dos nervos provenientes de L5 e L6 em $12,5 \%$ dos animais estudados, de L6 em $62,5 \%$ e de L6 e L 7 em $25 \%$ dos animais estudados. Após a sua origem, o nervo obturatório dirige-se ao forame obturatório, através do qual passa pelos músculos adutores da coxa.

O nervo isquiático apresentou formação a partir dos ramos nervosos ventrais de L6, L7, S1 e S2 em 50\% das análises feitas e de L7, S1 e S2 em 50\% das observações.

FIGURA 2: Fotomacrografia da região lombossacral da paca. D-nervo obturatório; F- nervo glúteo caudal; G- nervo isquiático; H- nervo pudendo. Escala de barra: $20 \mathrm{~mm}$.

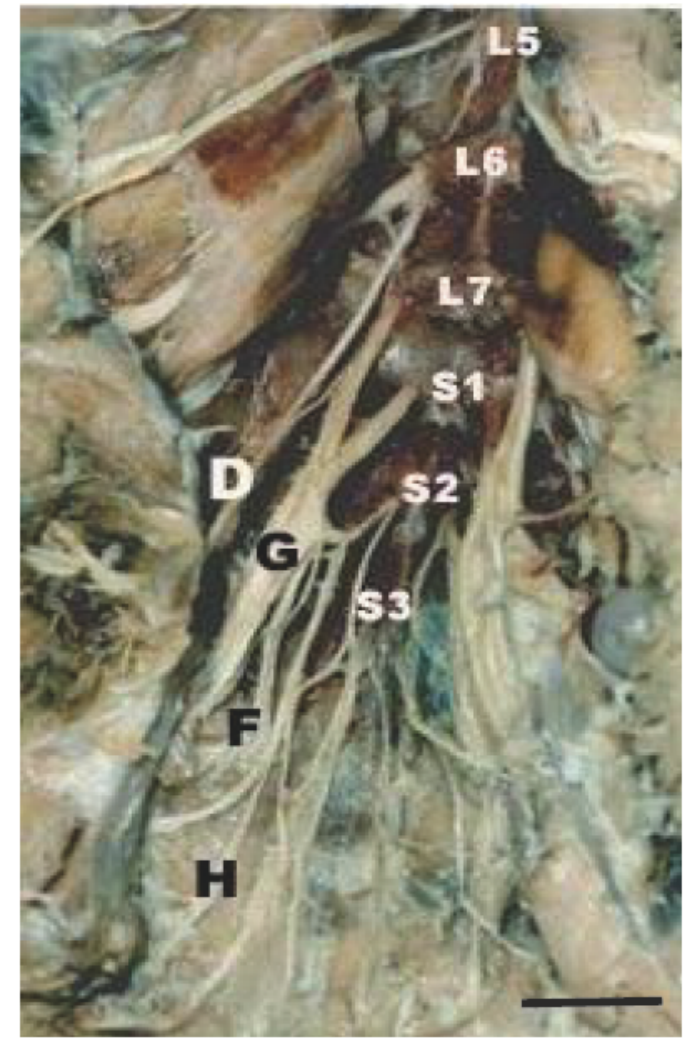

O nervo glúteo caudal originou-se de forma semelhante à origem do nervo isquiático, podendo ser possível diferenciação entre os mesmos analisando a região suprida por cada nervo. O nervo glúteo caudal corre junto ao nervo isquiático, porém suas origens não são exatamente as mesmas. O nervo glúteo caudal originou-se dos ramos nervosos de L7 e S1 em 12,5\% dos animais estudados e somente de S1 em 87,5\% das análises feitas. O nervo pudendo originou-se de forma constante ( $100 \%$ dos casos) de fibras nervosas provenientes dos ramos ventrais de S2 e S3.

\section{Discussão}

A origem do plexo lombossacral tem sido reportado pela união dos ramos ventrais dos nervos espinhas lombares e sacrais nos animais domésticos (GHOSHAL; GETTY, 1971; GHOSHAL, 1972; GETTY, 1986; EVANS; DE LAHUNTA, 2001; DYCE et al., 2010; KÖNIG; LIEBICH, 2011). A mesma origem também foi observada na paca e em outros roedores, como no esquilo vermelho, mocó, chinchila, porquinho da índia (COOPER; SCHILLER, 1975; LACERDA et al., 2006; AYDIN, 2010; MARTINEZ-PEREIRA; RICKES, 2011). No rato e no porco espinho, no entanto, o plexo lombossacral teve também a participação dos nervos torácicos T13 e T15, respectivamente (GREENE, 1955; AYDIN, 2009). Na paca, a origem do plexo lombossacral mais frequentemente observada foi a união dos ramos ventrais dos nervos lombares (L4-L7) e dos três ultimos ramos ventrais sacrais (S1-S2-S3), assemelhandose, desta forma, a origem do plexo lombossacral no gato, de acordo com descrição de Crouch (1969) e no coelho (MCLAUGLIN; CHIASSON, 1987), embora Ghoshal (1972) tenha descrito que a origem do plexo lombossacral no gato é formado a partir dos ramos ventrais dos últimos quatro nervos lombares e primeiro nervo sacral, sendo que o segundo nervo sacral pode contribuir com um pequeno ramo na sua formação.

Nas pacas, a formação do plexo lombossacral foi feita pelos nervos genito-femoral, cutâneo femoral lateral, femoral, gluteo cranial, obturatório, isquiático, gluteo caudal, pudendo e cutaneo femoral caudal, embora em cães, ratos, ovinos, chinchilas tenha sido descrito que os nervos ilio-hipogástrico cranial, ilio-hipogástrico caudal e ilio-inguinal também participam da formação do plexo lombossacral (BRADLEY, 1948; GREENE, 1955; GHOSHAL; GETTY, 1971; MARTINEZ-PEREIRA; ICKES, 2011) e no porco espinho, Aydin (2009) descreve a presença do nervo ilio-hipogástrico sem a sua divisão em cranial e caudal. 
O nervo genito-femoral nas pacas teve sua origem predominante em L4, nos cães, houve predominância de L3-L4 (FLETCHER, 1970) e foi reportada a participação do ramo ventral T15-L1 no porco espinho e L3 na chinchila (MARTINEZ-PEREIRA; RICKES, 2011). No porco espinho estes mesmos ramos ventrais também contribuiram para a formação do nervo cutâneo femoral lateral. Nas pacas, o ramo ventral de L5 foi predominante na sua formação.

O nervo femoral teve a participação de L5, L6 e L7 nas pacas analisadas, sendo L5-L6 prevalentes na sua formação. Na chinchila os ramos ventrais de L4-L5 contribuiram para a formação do nervo femoral, bem como no mocó, cuja participação de L4-L5 representou sua formação predominante (LACERDA et al., 2006; MARTINEZ-PEREIRA; RICKES, 2011).

Em metade das pacas analisadas, o nervo glúteo cranial teve a contribuição de L6-L7 na sua formação, o mesmo foi descrito por Ghoshal (1972) na espécie felina. Em algumas espécies de animais domésticos pode haver também a contribuição do primeiro ramo sacral (GETTY, 1986).

O sexto nervo lombar foi o maior formador do nervo obturatório na paca, seguido pela participação de L6-L7, no mocó a mesma participação de L6-L7 foi observada em animais com sete vértebras lombares (LACERDA et al., 2006).

O nervo isquiático foi o nervo que compreendeu o maior número ramos ventrais de nervos espinhais na sua formação, contando com a participação dos nervos lombares e sacrais. Em metade das pacas avaliadas, L6L7-S1-S2 fizeram parte da formação do nervo isquiático enquanto na outra metade, houve a contribuição de L7S1-S2. O sexto e sétimo nervo lombar e os dois primeiros sacrais foi predominante na formação do nervo isquiático no cão, de acordo com Fletcher (1970) e nos mocós com sete vértebras lombares (LACERDA et al., 2006). No preá houve o predomínio também do sexto e sétimo nervo lombar (OLIVEIRA et al., 2010).

O nervo glúteo caudal, embora tenha sido formado também por nervos lombares e sacrais, foi majoritariamente formado pelo primeiro nervo sacral na paca. No porco espinho, chinchila e mocó houve a participação de ambos os nervos na sua contituição (LACERDA et al., 2006; AYDIN, 2009; MARTINEZPEREIRA; RICKES, 2011).

Em todas as pacas avaliadas, o nervo pudendo foi formado por S2 e S3, o mesmo foi descrito no mocó (LACERDA et al., 2006) e em 20\% dos cães analisados por Fletcher (1970). Getty (1986) descreveu que o nervo pudendo frequentemente recebe ramos ventrais de todos os três nervos sacrais e as vezes é formado por S2 e $\mathrm{S} 3$ ou S1 e S2. Este nervo é considerado por muitos autores como plexo (GREENE, 1955), já que emite diversos ramos, responsáveis pela inervação da região anal, perineal e parte proximal da superfície caudal da coxa (GHOSHAL, 1972), além de originar ramos como o nervo retal caudal, nervos perineais e nervo dorsal do pênis ou do clitóris (EVANS; DE LAHUNTA, 2001).

O nervo cutâneo femoral caudal foi formado pelo terceiro nervo sacral na totalidade das pacas analisadas, no porco espinho e na chinchila, no entanto, ainda houve a participação dos nervos lombares na sua formação (AYDIN, 2009; MARTINEZ-PEREIRA; RICKES, 2011).

Mediante os resultados observados conclui-se que os nervos que formam o plexo lombossacral da paca são: nervo genito-femoral, nervo cutâneo femoral lateral, nervo femoral, nervo glúteo cranial, nervo obturatório, nervo isquiático, nervo glúteo caudal, nervo pudendo e nervo cutâneo femoral caudal.

\section{Agradecimentos}

À Fundação de Amparo à Pesquisa do Estado de São Paulo (FAPESP), processo número 02/09143-4, pelo apoio financeiro.

\section{Referências}

AYDIN, A. The dissemination of pelvic limb nerves originating from the lumbosacral plexus in the porcupine (Hystrix cristata). Veterinární Medicína, Praha, v. 54, n. 7, p. 333-339, 2009.

AYDIN, A. The spinal nerves that constitute the plexus lumbosacrales of the red squirrel (Sciurus vulgaris). Veterinární Medicína, Praha, v. 55, n. 4, p. 183-186, 2010.

BENTTI, S. B. Roedores da América Tropical. Natura, Caracas, v. 1, n. 70, p. 40-44, 1981. 
BRADLEY, O. C. Topographical anatomy of the dog. New York: The Macmillan Company, 1948. 284 p.

COOPER, G.; SCHILler, A. L. Anatomy of the Guinea Pig. Cambridge: Harvard University Press, 1975. 471 p.

CROUCH, J. E. Text-atlas of cat anatomy. Philadelphia: Lea \& Febiger, 1969. 399 p.

DYCE, J. M.; SACK, W. O.; WENSING, C. I. G. Tratado de anatomia veterinária. Rio de Janeiro: Elsevier, 2010. 834 p.

EVANS, H. E.; DE LAHUNTA, A. Guia para a dissecação do cão. Rio de Janeiro: Guanabara Koogan, 2001. 250 p.

FIEDLER, L. A. Rodents as a food source. In: DAVIS L. R.; MARSH R. E. (Ed.). Vertebrate Pest Conference Proceedings Collection. Davis: University of California Press, 1990. p. 148155.

FLETCHER, T. F. Lumbosacral plexus and pelvic limb myotomes of the dog. American Journal of Veterinary Research, Chicago, v. 31 , n. 1 , p. 35-41, 1970.

GETTY, R. Anatomia dos animais domésticos. Vol. 1. 5. ed. Rio de Janeiro: Guanabara Koogan, 1986. 2048 p.

GHOSHAL, N. G. The lumbosacral plexus (Plexus lumbosacralis) of the cat (Felis domestica). Anatomisher Anzeiger, Jena, v. 131, n. 3, p. 272-279, 1972.

GHOSHAL, N. G.; GETTY, R. The lumbosacral plexus (Plexus lumbosacralis) of the sheep (Ovis aries). New Zealand Veterinary Journal, Wellington, v. 19, n. 5, p. 85-90, 1971.

GREENE, E. C. Anatomy of the rat. Vol. 2. New York: American Philosophical Society, 1955. 370 p.

INTERNATIONAL COMMITTEE ON VETERINARY GROSS ANATOMICAL NOMENCLATURE. Nomina Anatômica Veterinária. 5. ed. Knoxville: World Association on Veterinary Anatomist, 2012. 190 p.

KLEIMAN, D. G.; EISENBERG, J. F.; MALIAK, E. Reproductive parameters and productivity of caviomorph rodents. In: EISENBERG, J. F. (Ed.). Vertebrate ecology in the northern Neotropics. 4 ed. Washington: Smithsonian Institution, 1979. p. 173-83.
KÖNIG, H. E; LIEBICH, H. G. Anatomia dos animais domésticos. Porto Alegre: Artmed, 2011. 787 p.

LACERDA, P. M. O.; MOURA, E. B.; MIGLINO, M. A.; OLIVEIRA, M. F.; ALBUQUERQUE, J. F. G. Origem do plexo lombossacral de mocó (Kerondo rupestris). Brazilian Journal of Veterinary Research and Animal Science, São Paulo, v. 43, n. 5, p. 620-628, 2006.

MARTINEZ-PEREIRA, M. A.; RICKES, E. M. The spinal nerves that constitute the lumbosacral plexus and their distribution in the chinchilla. Journal of South African Veterinarian Association, Pretoria, v. 82, n. 3, p. 150-154, 2011.

MASSONE, F. Anestesiologia veterinária: farmacologia e técnicas. Rio de Janeiro: Guanabara Koogan, 1999. 226 p.

MATAMOROS, Y. Investigaciones preliminares sobre la reproducción, comportamiento, alimentación y manejo tapezcuinte (Cuniculus paca, Brisson) en cativeiro en Salinas. In: CONGRESO LATINOAMERICANO DE ZOOLOGÍA, VIII, 1982, Salinas. Anais... Salinas: Zoología Neotropical, 1982. p. 902-961.

MCLAUGHLIN, C. A.; CHIASSON, R. B. Laboratory anatomy of the rabbit. Dubuque: W.C Brown Company, 1987. 124 p.

MOCKRIN, M. H.; BENNET, E. L.; LABRUNA, D. T. Wildlife farming: a viable alternative to hunting in tropical forests? New York: WCS Working Paper No 23, Wildlife Conservation Society, 2005. $32 \mathrm{p}$.

MONDOLFI, E. La laca o Paca. Defensa de la naturaleza, Caracas, v. 2, n. 5, p. 4-16, 1972.

OLIVEIRA, G. B.; RODRIGUES, M. N.; SOUSA, E. S.; ALBUQUERQUE, J. F. G.; MOURA, C. E. B.; AMBROSIO, C. E.; MIGLINO, M. A.; OLIVEIRA, M. F. Origem e distribuição dos nervos isquiáticos do preá. Ciência Rural, Santa Maria, v. 40, n. 8, p. 1741-1745, 2010. 